\title{
Efficacy, safety, and patient acceptability of the combined chlormadinone acetate-ethinylestradiol oral contraceptive
}

This article was published in the following Dove Press journal:

Open Access Journal of Contraception

I September 2010

Number of times this article has been viewed

\section{Serena Ferrari \\ Marianna Cannoletta \\ Matteo Generali \\ Lucia Cazzato \\ Angelo Cagnacci}

Department of Obstetrics, Gynecology, and Pediatrics, Azienda Ospedaliero, Universitaria di Modena, Italy
Correspondence: Angelo Cagnacci

Obstetrics and Gynecology,

Department of Obstetrics

Gynecology and Pediatrics, Azienda

Ospedaliero, Universitaria od Modena,

via del Pozzo 7I, 4100 Modena, Italy

$\mathrm{Tel}+3905942245 \mathrm{II}$

Fax +39059422 4394

Email cagnacci@unimore.it

\begin{abstract}
Since their introduction in 1959, development of hormonal contraceptives has been ongoing, with the ultimate aim of creating not only an effective and safe contraceptive method, but also a drug able to meet the need for treatment of other conditions, such as acne, seborrhea, and hirsutism, with few or no side effects. With this objective, a new progestin, chlormadinone acetate (CMA), has been developed as a derivative of progesterone for contraception. This new molecule has been introduced in combination with ethinylestradiol (EE) $30 \mu \mathrm{g}$ as a safe contraceptive with antiandrogenic properties. Many clinical studies have investigated this new oral combination and found it to be safe, with a Pearl Index similar to that of other combined hormonal contraceptives. CMA, because of its antiandrogenic properties, has been also considered effective for resolution of acne, seborrhea, and hirsutism. The data show it to be a safe molecule in terms of glucose and lipid metabolism. No major weight changes have been linked with its use, and it seems to be the only progestin able to reduce fat mass during use. The CMA-EE combination is well tolerated and acceptable to women. Adverse events related to its use are similar to those reported with other third-generation contraceptives. We can conclude that CMA-EE is an effective, safe, and well tolerated antiandrogenic hormonal contraceptive.
\end{abstract}

Keywords: chlormadinone acetate, acne, weight, metabolism, safety, hormonal contraceptive

\section{Introduction}

The use of combined oral contraceptive pills has steadily increased since their introduction in 1960. Currently over 80 million women worldwide rely on hormonal contraception, expecting it to provide optimal contraceptive efficacy with a reliable tolerability profile, and additional benefits for well being. After the first oral contraceptive products became available to the general population, concern about adverse reactions led to a modification in their composition, ie, a lower estrogen dose and the introduction of new progestogens. Chlormadinone acetate (CMA), a synthetic progestogen, in combination with ethinylestradiol (EE), was approved in Germany in 1998 as a combined hormonal oral contraceptive.

CMA is a derivative of 17-alfa-hydroxyprogesterone. In in vitro studies, CMA showed a high affinity for progesterone receptors, about one-third higher than for progesterone itself. ${ }^{1} \mathrm{CMA}$, like the other antiandrogenic progestogens, shows no affinity for estrogen receptors in vitro, suggesting an absence of estrogenic effects at clinically relevant doses. ${ }^{2}$ The progestogenic activity of CMA produces a negative feedback on gonadotropin secretion, leading to inhibition of ovulation and reduced androgen biosynthesis. ${ }^{3}$ CMA also has antiandrogenic properties, mainly exerted 
by blockade of androgen receptors in target organs, but also by reduction of activity in sebaceous glands and hair follicles by 5 -alpha reductase, the enzyme responsible for converting testosterone to the more potent androgen, 5-alpha dihydrotestosterone. ${ }^{4}$ Furthermore, CMA does not compete with androgens for sex hormone-binding globulin and, by suppressing gonadotropin secretion, it reduces ovarian androgen production. CMA has negligible or no systemic glucocorticoid, mineralocorticoid, or antimineralocorticoid effects at clinically relevant doses. ${ }^{5}$

\section{Pharmacokinetics}

After oral administration, CMA is almost completely absorbed at peak plasma concentration in 1-4 hours, and its bioavailability is almost $100 \%$. During multiple dose administration, CMA exhibits linear time-dependent pharmacokinetics, with little accumulation in plasma. Multiple dose administration has little impact on peak plasma concentrations, although the terminal elimination half-life is increased compared with single-dose administration. Nevertheless, steady-state plasma concentrations are achieved within 8-15 days. CMA is over $96 \%$ bound to plasma albumin. ${ }^{6}$ Antiandrogenic progestogens have no affinity for sex hormone-binding globulin, and therefore they do not displace androgens from their carrier proteins. ${ }^{7}$ Importantly, CMA does not antagonize the EE-induced increase in sex hormone-binding globulin production. ${ }^{8}$ CMA is highly lipophilic, so is taken up by body fat and is also stored in some reproductive tissues, such as the myometrium, cervix, and fallopian tubes. ${ }^{9}$ Storage in body fat slows elimination, but clinically relevant accumulation of CMA (which may be manifested by delayed withdrawal bleeding) is only apparent in some women taking high doses ( $\geq 10 \mathrm{mg} /$ day) to treat androgen-related conditions. ${ }^{7}$

CMA undergoes extensive hepatic metabolism before excretion in the urine and feces. The main metabolites of CMA in human plasma are its $2 \alpha-, 3 \alpha-$, and $3 \beta$-hydroxy derivatives, although a wide variety of other reduced, hydroxylated, and deacetylated metabolites are also formed. ${ }^{7}$ There is some controversy over the activity of the $3 \alpha$ - and $3 \beta$-hydroxy metabolites. Animal studies have indicated them to be antiandrogenic, while others suggest that this activity might result from back-transformation into CMA because an intact 3-keto group appears to be essential for androgen receptor binding. Other CMA metabolites are inactive. ${ }^{10}$ Because of its extensive distribution in fat, CMA is excreted slowly, with terminal elimination half-life values of around 25 hours after a single dose and 36-39 hours after multiple doses. CMA is excreted approximately equally in the urine and feces ( $45 \%$ and $42 \%$, respectively). ${ }^{11}$

\section{Efficacy Contraceptive efficacy}

On the basis of many dedicated studies, the combination of CMA-EE can be described as an effective oral contraceptive. A Phase II, single-center, open, uncontrolled trial was performed to evaluate the efficacy of CMA-EE in the prevention of pregnancy. The main outcome measure was inhibition of ovarian activity, assessed by frequent ultrasound monitoring of the presence, size, and persistence of follicle-like structures. Secondary parameters included cervical reaction score (ie, probability of fertilization), endometrial thickness (probability of implantation), and serum levels of the sex hormones estradiol, progesterone, luteinizing hormone, and follicle-stimulating hormone. Thirty-three subjects were eligible for the trial and were included in the efficacy assessment (per protocol analysis). All subjects ovulated during the pretreatment cycle, but none ovulated during the three medication cycles. Follicular growth was profoundly suppressed during the medication phase, with residual ovarian activity occurring in only 12/83 (14.5\%) treatment cycles. The cervical reaction score was negative during each medication cycle, and endometrial thickness was suppressed on each medication day, with median values of $4.0-6.0 \mathrm{~mm} .^{12}$

An open, uncontrolled Phase III study evaluated the CMAEE combination in terms of efficacy. A total of 1655 women, who were patients of 75 office-based gynecologists in Germany, participated in the study and were treated with CMA-EE for $\leq 24$ cycles, ie, a total of 22,337 cycles. Twelve pregnancies occurred during the study. The actual Pearl Index was 0.645 (95\% confidence interval [CI]: 0.359-1.092); in seven of these pregnancies, conception occurred because of intake errors, concomitant administration of antibiotics, diarrhea, or vomiting. Thus, the theoretic Pearl Index in this study was 0.269 (95\% CI: 0.109-0.600). The cumulative 12-cycle pregnancy rate was 0.00232 (95\% CI: 0.0-0.0049) considering only the pregnancies contributing to the theoretic Pearl index, and 0.00525 (95\% CI: 0.00135-0.00914) considering all pregnancies. After 24 cycles, the cumulative pregnancy rate was 0.0046 (95\% CI: $0.00047-0.00873)$ and 0.01385 (95\% CI: $0.0038-0.0239)$, respectively. ${ }^{13}$

Another open, multicenter, observational clinical evaluation was conducted, also in Germany, in which 2620 patients from 435 gynecologic practices were treated for $<12$ months. The analysis thus encompassed 29,262 cycles of exposure. Ten women became pregnant during the 12-month observa- 
tion period. Thus, the unadjusted Pearl Index was calculated to be 0.4 (95\% CI: 0.2-0.8). However, intake errors were considered to be responsible for $90 \%$ of the undesired pregnancies, which included at least $8 / 9$ patients who forgot to take the pill on several occasions. After review, in only one case was a method failure stated as possible, resulting in an adjusted Pearl Index of 0.04 (95\% CI: 0.002-0.2). ${ }^{14}$

Another trial involved 3772 women aged $\geq 25$ years who used contraception for six cycles with a conventional or extended cycle regimen. The total number of observed cycles was 21,642.25 for both the conventional cycle regimen (20,707 cycles) and extended cycle regimen (363 extended cycles, ie, 935.25 cycle equivalents at 28 days), with an observation period of 1665 women-years (based on 13 cycles/cycle equivalents of 28 days). The conventional cycle regimen for CMA-EE (21-day pill intake [one blister strip pack] followed by a seven-day, pill-free interval) was used by 3578 (94.9\%) women, with only a minority of women $(n=194,5.14 \%)$ using an extended cycle regimen with a consecutive pill intake of two to six (most often three) blister strip packs of CMA-EE $(n=116$, $59.79 \%$ ) followed by a seven-day, pill-free interval.

A total of $3276(86.85 \%)$ women reported regular intake of CMA-EE, whereas the remainder missed at least one $(n=369)$ or more $(n=127)$ tablets per cycle/blister strip pack. Despite these irregularities, no pregnancy occurred during CMA-EE treatment. This resulted in a Pearl Index of 0 (95\% CI: $0.00-0.22){ }^{15}$

The efficacy of CMA-EE (2 mg and $20 \mu \mathrm{g}$, respectively) was also confirmed during the extended regimen. Six pregnancies occurred during 21,495 evaluable cycles, resulting in an overall Pearl Index of $0.36(95 \%$ CI: 0.13-0.79). This corresponds to an overall Pearl Index for the first year of use in women aged 18-40 years $(17,031$ cycles in 1653 subjects) and in women aged up to 35 years $(15,668$ cycles in 1524 subjects) of 0.31 and 0.33 , respectively.

The cumulative one-year pregnancy rate for the overall Pearl Index was 0.31\% (95\% CI: 0\%-0.61\%), corresponding to more than $99 \%$ contraceptive protection over one year. In five of six pregnancies, conception occurred at time points for which the efficacy of CMA-EE ( $2 \mathrm{mg}$ and $0.02 \mathrm{mg}$, respectively) was reduced due to vomiting, diarrhea, and intake errors. Only one pregnancy was attributable to method failure. ${ }^{16}$

\section{Acne}

Acne is a common skin disorder characterized by overproduction of sebum leading to noninflammatory (comedones) and inflammatory (papules, pustules, nodulocystic lesion) skin conditions. Most women with acne suffer from a hypersensitivity of the sebaceous glands to androgen, but frequently an excess of androgen can be observed. The use of an oral contraceptive with antiandrogenic properties has proven to be a useful approach towards this problem. A study developed by Worret et $\mathrm{al}^{17}$ compared the effects of two low-dose estrogen-progestogen combinations, ie, CMA-EE and $\mathrm{EE}$ in combination with levonorgestrel (LNG-EE), in 199 women with mild to moderate papulopustular acne. The primary endpoint was achieved if the number of papules/ pustules per half of the face present on admission had decreased by at least $50 \%$ in medication cycle 12 . In total, for papulopustular facial acne, 59.4\% patients on CMA-EE and $45.9 \%$ patients on LNG-EE were responders according to the definition of the primary endpoint; this superiority was statistically significant. Similar trends could be detected for comedonal facial acne by cycle 12 . With CMA-EE, an improvement of $88.9 \%$ was seen compared with $77.3 \%$ in the LNG-EE group. The improvement rates for papulopustular or comedonal acne were $95.6 \%$ and $91.9 \%$, respectively, on CMA-EE compared with $81.1 \%$ and $73.1 \%$ on LNG-EE. Papulopustular acne, as well as comedonal acne of the back, improved in almost $100 \%$ patients on CMA-EE $(97.7 \%$ and $97.3 \%$, respectively) and in a smaller number of patients on LNG-EE (87.9\% and 76.9\%, respectively).

Another double-blind, randomized (2:1), placebocontrolled, parallel, multinational Phase III trial was conducted to evaluate acne resolution on CMA-EE. ${ }^{18}$ This trial showed clearly that CMA-EE was superior to placebo in the treatment of moderate acne, irrespective of the kind of lesion or the body area under investigation. The trial included 387 subjects from 28 European centers. Ten subjects did not take any study medication and were therefore excluded from evaluation. Therefore, the analysis included 251 subjects randomized to receive CMA-EE and 126 to placebo. The primary endpoint of the study was reduction of moderate papulopustular facial acne. The rate of response was significantly higher in the CMA-EE group, ie, 64.1\% (161/251) compared with $43.7 \%(55 / 126)$ for placebo $(P=0.0001)$. A similar trend in favor of CMA-EE was observed for moderate comedonal facial acne. During treatment, a continuous reduction in comedones occurred in both groups, but a pronounced effect was observed in women on CMA-EE. By medication cycle 6, the median relative decrease in comedones of the face was $54.8 \%$ in the CMA-EE group but only $32.4 \%$ in the placebo group (between-group difference $P=0.0006$ ). In cycles 3 and 6, the $P$ value for the between-group difference in relation to 
the relative change from baseline in comedone number was $P<0.05$. On admission, $64.9 \%$ (163/251) of subjects in the CMA-EE group and 74.6\% (94/126) in the placebo group had moderate acne. In this subgroup analysis, the number who experienced complete resolution of moderate acne on the décolleté increased continuously over the six cycles, with $48.5 \%$ (79/163) of CMA-EE subjects and 29.8\% (28/94) placebo subjects, having no moderate acne in this area at all by the end of the trial. The median relative decrease from baseline in papules and/or pustules over six cycles was $92.9 \%$ in the CMA-EE group compared with only $50.0 \%$ in the placebo group $(P<0.05$ at cycle 3 and cycle 6$)$. Prevalence of moderate acne on the back was high, ie, $80.1 \%(201 / 251)$ in the CMA-EE group and $86.5 \%(109 / 126)$ in the placebo group at baseline. There was a continuous reduction in papulopustular lesions on the back over six cycles in the CMA-EE group, resulting in a median relative decrease of $86.0 \%$ compared with $58.3 \%$ in the placebo group. The $P$ value for the relative difference between groups versus baseline was $P<0.05$ for cycles 3 and 6 . Complete resolution of moderate acne lesions on the back was found in $41.8 \%$ of the CMA-EE group and $24.8 \%$ of the placebo group.

An open-label, prospective, single-center Phase IV study investigated the effects of CMA-EE on the physiology of acne-prone facial skin in healthy women aged $18-37$ years. ${ }^{19}$ The condition of facial skin, as quantified by a clinical summation score, improved significantly after three and six treatment cycles, with reduced numbers of acne lesions (comedones and papules/papulopustules) and a reduction in degree of seborrhea. Skin surface $\mathrm{pH}$ remained within the normal physiologic range, and there was an improvement in epidermal barrier function (as manifested by decreased transepidermal water loss from the skin of the forehead). Stratum corneum hydration increased, and the lipid content of the skin surface on the forehead decreased.

The superiority of CMA-EE for acne improvement in comparison with other contraceptive methods has also been demonstrated in another study ${ }^{20}$ which observed users of oral contraceptives, intrauterine devices, and intrauterine systems, who switched voluntarily to CMA-EE treatment because of dissatisfaction with their earlier contraceptive regimen. The majority of study participants $(12,088,72.0 \%)$ complained about seborrhea and/or acne while on their previous hormonal contraceptive regimen. Before and after four cycles of CMA-EE, data for this complaint were available for 11,638 women. In almost half of them (45.9\%), seborrheic symptoms disappeared completely after switching to CMA-EE during a four-cycle treatment. Acne/seborrhea improved in another $36.5 \%(\mathrm{n}=4248)$. Acne can have a profound negative impact on well-being, particularly during adolescence. A study in this population found CMA-EE to be a good contraceptive compared with drospirenone (DRSP). Prior to the study, 90 adolescents (55.5\%) complained of acne, and 84 (52.4\%) complained of skin disorders with a predominance of greasy skin. Objective amelioration of skin and hair features was found in both groups, but there was a significantly greater benefit in CMA users compared with DRSP users at the end of the study $(P<0.01){ }^{21}$

\section{Seborrhea and hirsutism}

The studies that investigated acne in women taking CMAEE also investigated seborrhea and hirsutism. In comparison with placebo, total resolution of seborrheic symptoms was observed in $41.5 \%$ of subjects taking CMA-EE and in $23.9 \%$ taking placebo (95\% CI: 51.1-65.6 and 65.9-84.6, respectively). ${ }^{18}$ Seventeen percent of subjects experienced total resolution of hirsutism in the CMA-EE group versus $8.8 \%$ in the placebo group (95\% CI: 70.6-91.4 and 76.3-98.1, respectively). In comparison with $\mathrm{LNG-EE},{ }^{17}$ an improvement in seborrhea and hirsutism was confirmed. At baseline, 31.7\% of women on CMA-EE and $30.6 \%$ on LNG-EE suffered from seborrhea. In both treatment groups, there was a decrease in the number of women with seborrhea after 12 treatment cycles; $80.0 \%$ in the CMA-EE group showed total resolution versus $76.2 \%$ in the LNG-EE group. Hirsutism, irrespective of body localization, was present in $13.9 \%$ of patients allocated to CMA-EE and in $20.4 \%$ on LNG-EE at baseline. Hirsutism disappeared completely in about one-third of women in each treatment group after 12 cycles of treatment. Even if these data can be considered only a trend because of the small patient population, it is possible to consider CMA to have a good profile also in hirsutism. ${ }^{17}$

\section{Safety}

Over the years many studies have investigated the safety profile of hormonal contraception. The attention of clinicians was mainly focused on the most important risk factors for thrombosis and cardiovascular diseases (hemostatic parameters, blood pressure, lipids, and glucose metabolism).

An increased risk of thromboembolic events with oral contraceptives has been recognized since 1970. In particular, this risk was attributed to the estrogen dose, and later to the type of progestin in the combination. The effect of CMA-EE on hemostatic parameters was evaluated in 45 volunteers randomly assigned to six months of treatment with CMA-EE or a combination desogestrel (DSG)-EE oral 
contraceptive pill. This study demonstrated that both oral contraceptive combinations had comparable effects on the hemostatic system. There was a shift towards a new equilibrium of hemostatic activity, both coagulatory and fibrinolytic, with a higher turnover rate. The changes did not exceed the normal range and were comparable with the published effects of other low-dose hormonal contraceptives. In particular, increased plasma levels of fibrinogen, Factor VII, VIII, and XIII activity, and prothrombin fragments 1 and 2 were documented for CMA-EE. Plasma levels of thrombinantithrombin complexes showed no alteration. A decrease in antithrombin III and protein S activity was found, as well as a decrease in activated protein $\mathrm{C}$ sensitivity and an increase in protein $\mathrm{C}$ activity. The use of CMA-EE was associated with an increase in plasmin-antiplasmin complexes, D-dimer, and total fibrin degradation products. Both tissue plasminogen activator and its inhibitors decreased considerably, but the decrease in plasminogen activator inhibitor-1 exceeded the decrease in tissue plasminogen activator, suggesting the surplus activity of the fibrinolytic system was associated with a reduced threshold of fibrinolytic inhibition. ${ }^{22}$

A second study was conducted using CMA in combination with a lower EE dose of $20 \mu \mathrm{g}$. Thrombin/fibrin turnover was assessed by analysis of D-dimer concentrations and prothrombin fragment 1 and 2 concentrations. The median D-dimer values (fibrin turnover) did not change between baseline and CMA-EE cycle 6. Median prothrombin fragment 1 and 2 values (thrombin turnover) increased by $33.3 \%$ between baseline and medication cycle $6(P<0.05$ compared with baseline) during treatment with CMA-EE. The majority of changes in prothrombin fragment 1 and 2 and D-dimer remained within the reference range. Median values for all procoagulatory parameters (fibrinogen, and Factor II, VII, and VIII activity) increased between baseline and medication cycle 6. During the postmedication cycle, these changes returned towards baseline values. Between $80 \%-95 \%$ of all fibrinogen and Factor VIII activity values remained within the reference range throughout the trial. Factor II and VII activity changed from normal at baseline to above the upper limit of normal at medication cycle 6 . The median values for the anticoagulatory parameters, activated partial thromboplastin time, activated protein $\mathrm{C}$ sensitivity ratio, antithrombin III activity, and free protein $\mathrm{S}$ decreased to a small extent ( $<15 \%$ change from baseline), or remained unchanged between baseline and medication cycle 6 . In contrast, protein $\mathrm{C}$ activity and endogenous thrombin potential-based activated protein $\mathrm{C}$ resistance increased between baseline and medication cycle $6(P<0.05)$. Most changes returned towards baseline during the postmedication cycle. Plasminogen, a profibrinolytic parameter, increased $(P<0.05)$ and tissue plasminogen activator decreased $(P<0.05)$ between baseline and medication cycle 6 . Plasminogen activator inhibitor Type 1 antigen (an antifibrinolytic parameter), decreased by $4 \%-69 \%$. The majority of the changes during medication cycle 6 remained within the reference range, and most changes returned towards baseline during the postmedication cycle. ${ }^{23} \mathrm{CMA}-\mathrm{EE}$ was associated with a lower risk of deep vein thrombosis than other thirdgeneration hormonal contraceptives. ${ }^{13,14,22}$

CMA-EE has a neutral effect on blood pressure. Systolic/ diastolic blood pressure and heart rate remained unchanged in 1600 women during administration of CMA-EE. ${ }^{13}$ Blood pressure was unchanged also during longer treatment or during an extended regimen. ${ }^{14-16}$ Many studies have demonstrated that lower-dose oral contraceptives have no clinically relevant influence on glucose metabolism, including development of diabetes mellitus. Glucose intolerance and insulin resistance are associated with an increased risk of atherosclerosis and cardiovascular disease. A trial evaluating metabolic changes during use of CMA investigated changes in blood glucose and insulin levels with the oral glucose tolerance test. Treatment with CMA-EE (2 mg and $30 \mu \mathrm{g}$, respectively) increased blood glucose levels compared with baseline during the oral glucose tolerance test, although the values were still within the reference range. Insulin plasma levels were also slightly increased in parallel with the raised glucose levels. None of the subjects in the treatment group had an abnormal oral glucose tolerance test suggestive of impaired glucose tolerance or diabetes mellitus. ${ }^{24}$

The oral glucose tolerance test is not appropriate for evaluation of insulin sensitivity, reduction of which represents the first step in deterioration of glucose metabolism. Insulin sensitivity was investigated with a frequently sampled intravenous glucose tolerance test and the minimal model method in 39 women on an oral contraceptive containing DSG versus an oral contraceptive containing CMA. ${ }^{25}$ The results showed that the two contraceptive agents act differently. DSG-EE significantly decreases insulin sensitivity, while CMA-EE does not (Figure 1). This difference is probably related to the androgenic properties of DSG. ${ }^{25}$ Neutrality of CMA-EE on insulin sensitivity is important because it indicates that the compound does not favor development of the metabolic syndrome, of which insulin resistance and glucose metabolism alteration are the key determinants.

Data on lipids and lipoproteins are reassuring. A safety study was done in 1998 on 1655 women for a total of 


\section{Insulin sensitivity}

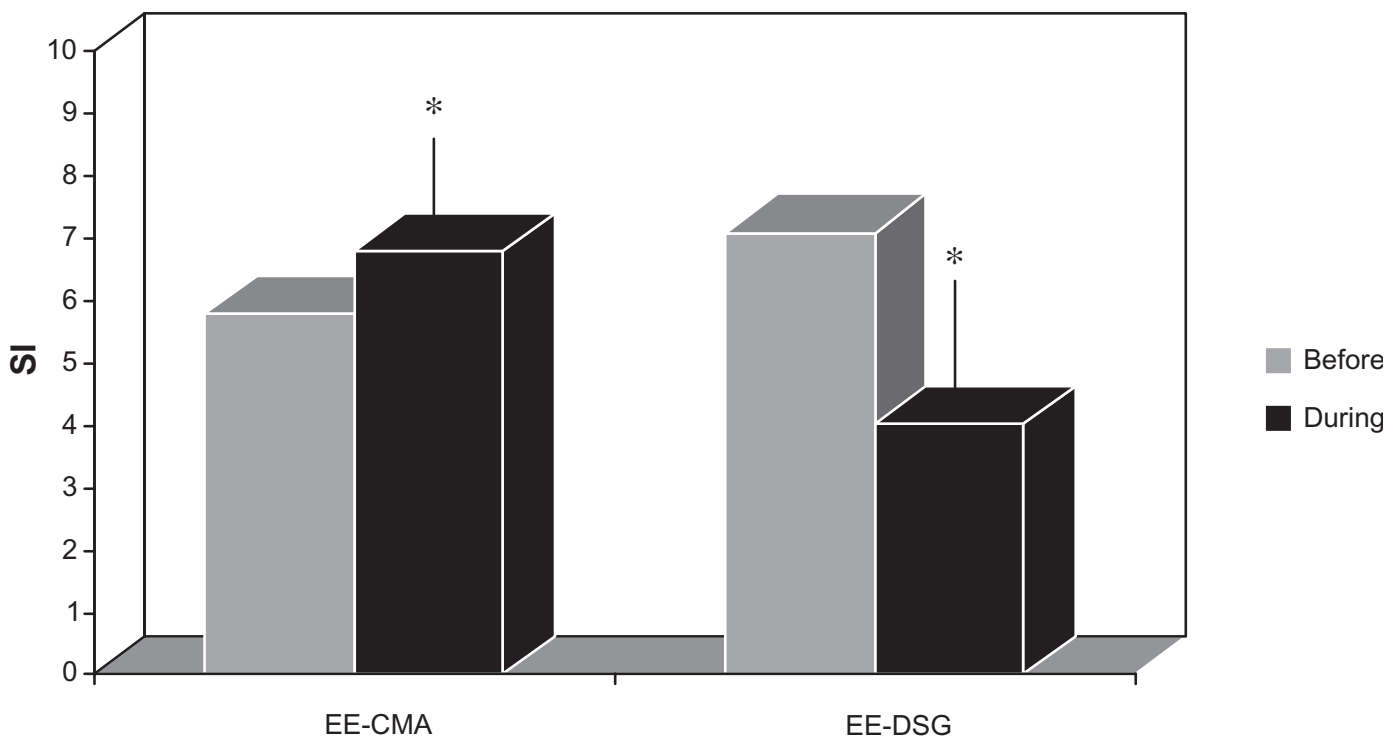

Figure I Mean $( \pm S E)$ peripheral insulin sensitivity (units $\pm 10^{-4} \mathrm{~min}^{-1} \mu / \mathrm{mL}$ ) observed in healthy young women before and after six months of treatment with DSG-EE $(n=I 2$ ) or CMA-EE $(n=12) ;{ }^{*} P=0.04$ versus corresponding baseline values. ${ }^{25}$

Abbreviations: CMA-EE, chlormadinone acetate-ethinylestradiol; DSG-EE, desogestrel-ethinylestradiol; SE.

22,337 cycles. In this study, it was reported that total triglycerides and very low-density lipoproteins (VLDL) increased during CMA-EE treatment, but on the other hand, the increase in median high-density lipoprotein (HDL) levels and a corresponding marked decrease in median low-density lipoprotein (LDL) values led to a decreased LDL:HDL ratio. ${ }^{13}$ A Phase III study performed in Germany claimed, without reporting data, an increase in total cholesterol and LDL levels, with a slight increase in mean HDL, and a slight increase in median VLDL, with no overall change in the LDL:HDL ratios. ${ }^{26}$ These data were recently confirmed and published for a small number of subjects, in whom CMA-EE was associated with elevated HDL and triglycerides, and these effects were strong enough to increase the HDL:LDL and Apo A1:Apo B ratios significantly (Figure 2). ${ }^{25}$ The relative risk of developing cardiovascular disease is inversely related to plasma HDL and Apo A1 concentrations and the LDL:HDL ratio, so all these findings show no evidence that CMA-EE increases the risk of atherogenic disease during long-term use.

Lipid metabolism has also been investigated during an extended regimen of CMA-EE. Although mean total cholesterol and LDL levels increased slightly during the study, there was also a slight increase in mean HDL. Consequently, there was no overall change in the LDL:HDL or total cholesterol:HDL ratios. Therefore, consistent with experience from use of other low-dose oral contraceptives, there is no evidence that CMA-EE (2 mg and $0.03 \mathrm{mg}$, respectively) increases the risk of developing atherosclerosis during long-term use. ${ }^{16}$

\section{Tolerability Cycle control}

A postmarketing surveillance study of CMA-EE shows it to be a well tolerated oral contraceptive. A "very good" or "good" tolerability was reported by $8.5 \%$ of women. ${ }^{27}$ During treatment, $69.6 \%$ of women did not experience any bleeding disorder. Withdrawal bleeding was assessed to be mild in 6977 (32.0 versus $21.9 \%$ at baseline), normal in 13,457 (61.7 versus $62.6 \%$ at baseline), and severe in 267 women (1.2 versus $14 \%$ at baseline). Both severe withdrawal bleeding and dysmenorrhea decreased markedly on CMA-EE. Almost two-thirds of women who previously experienced intracyclic bleeding reported that these symptoms had disappeared on CMA-EE. This was also the case for more than $90 \%$ of women with previous amenorrhea. About one-third of all patients did not experience any intermenstrual bleeding (spotting) or breakthrough bleeding, and the rates of cycles without intracyclic bleeding increased with the duration of study treatment. Amenorrhea was limited to a very low rate of only $1.0 \%$ for all cycles. ${ }^{27}$

Good cycle control with CMA-EE was also reported in a larger study conducted in 2620 women. While on CMA-EE, $67.3 \%$ of these women did not experience any bleeding problems. Slight spotting, breakthrough bleeding, and amen- 


\section{Lipid metabolism}

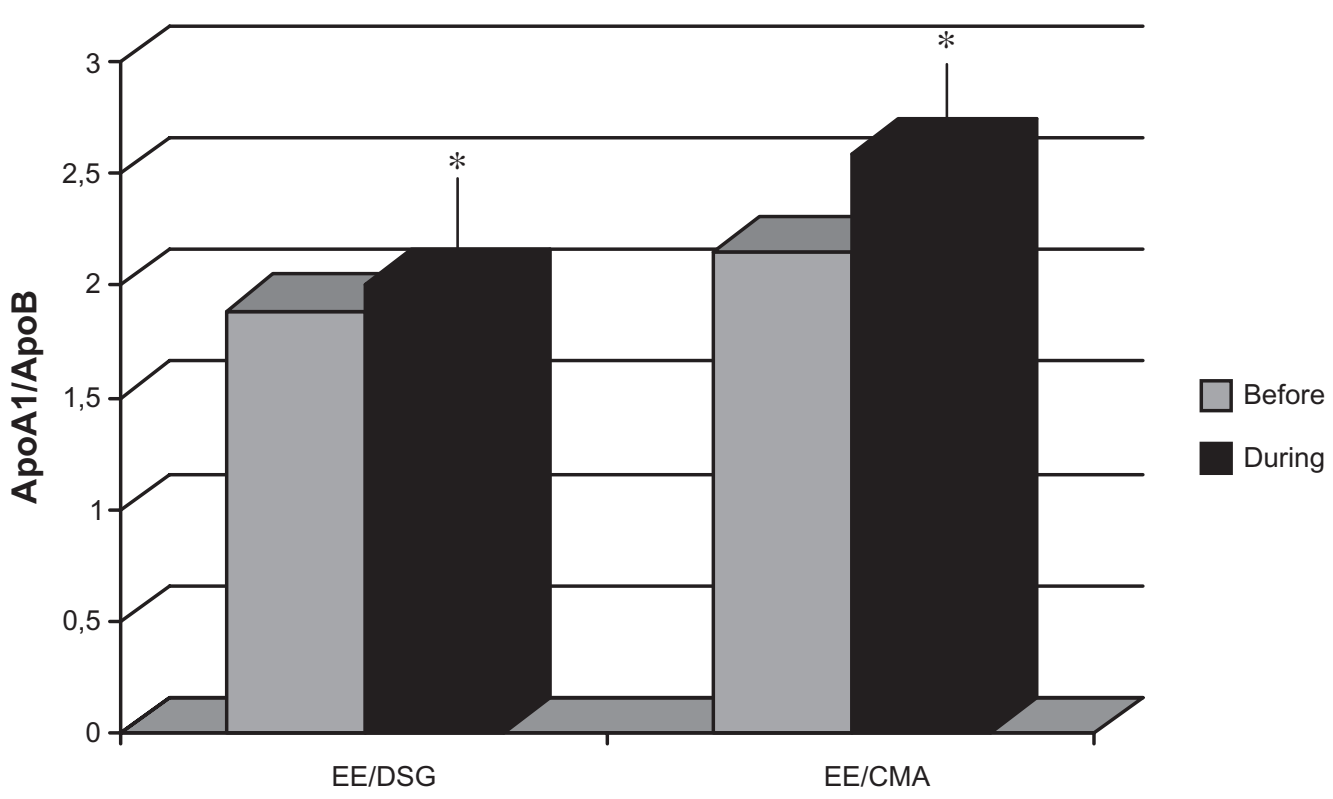

Figure 2 Mean (+SE) ApoAI/APo B observed in healthy young women before and after six months of treatment with DSG-EE $(n=12)$ or CMA-EE $(n=12)$; ${ }^{*}=0.048$ versus corresponding baseline values. ${ }^{25}$

Abbreviations: CMA-EE, chlormadinone acetate-ethinylestradiol; DSG-EE, desogestrel-ethinylestradiol; SE.

orrhea were documented in $26.6 \%, 7.1 \%$, and $6.4 \%$ of the total study population, respectively. In women with a history of regular cycles, the rates of menstrual bleeding problems were always below the average for all patients (spotting $21 \%$, breakthrough bleeding 5.7\%, and amenorrhea 5.4\%). In 81.4\% of women with no withdrawal bleeding, it was reported that amenorrhea occurred only in one cycle. Intermenstrual bleeding was most common during the first treatment cycle, and thereafter its incidence decreased. In $61.7 \%$ of women who suffered from intermenstrual bleeding in the last two cycles before the start of the study, the symptoms were no longer present when on CMA-EE. Amenorrhea disappeared in 89.3\% of these women. ${ }^{14}$

In comparison with DRSP, women using CMA had a significantly greater improvement of irregular bleeding after three cycles of therapy, which was progressive until the end of the observation period (CMA versus DRSP, $P<0.001$ ). The same trend was found for mild and moderate dysmenorrhea (CMA versus DRSP $P<0.01) .{ }^{21}$

Menstrual cycle irregularities are common in women when switching their method of contraception. The results of a prospective observational study in 20,897 women revealed that $87.0 \%(\mathrm{n}=2731)$ of participants who described their previous cycles as irregular reported regular cycling on CMA-EE. Irregular cycling was documented in only $6.9 \%(n=217)$ of women during the observation period. In total, 6073 women
(36.2\%) complained of spotting and breakthrough bleeding on their previous contraceptive regimen, but only 2391 women (14.2\%) has this complaint on CMA-EE. The number of women suffering from these symptoms decreased substantially to $3723(22.2 \%)$ and $692(4.1 \%)$, respectively, after four cycles of CMA-EE. The incidence of severe withdrawal bleeding dropped from $7.5 \%$ at baseline to $0.9 \%$ at the end of the evaluation period. A total of $2490(100 \%)$ women switched to the CMA-containing contraceptive because of secondary amenorrhea. On CMA-EE, bleeding occurred regularly in $87.6 \%(n=2180)$ of these women. If bleeding disorders were newly diagnosed during CMA-EE treatment, these difficulties mostly occurred in the first two cycles and became less frequent during further treatment. ${ }^{20}$

\section{Body weight}

CMA-EE is not linked with weight gain for the majority of women. In a study of long-term use, mean weight change was $0.8 \%$ in cycle $2,0.75 \%$ in cycle $4,1.0 \%$ in cycle 10 , and $0.22 \%$ in cycle $22 .{ }^{13}$ This good profile was confirmed by another study in 2620 women over 12 cycles, in which $78.8 \%$ of 2620 women did not experience major weight changes (loss or increase $>2 \mathrm{~kg}$ ) during CMA-EE, $24.5 \%$ of women did not report any weight change, and 36.5\% did experience a weight gain of $1-2 \mathrm{~kg} .{ }^{14}$ These findings were confirmed by a study in which body composition was 
evaluated using multifrequency bioelectrical impedance analysis in 24 women during the follicular phase before and after three and six cycles of CMA-EE. Mean values for body weight, body mass index, and waist-to-hip ratio did not vary during the study. Total body water, extracellular water, intracellular water, and fat free mass remained unchanged on CMA-EE. During treatment, mean fat mass was $13.5 \pm 1.0 \mathrm{~kg}$ after three months and $12.7 \pm 1.0 \mathrm{~kg}$ after six months. These values were significantly lower than the baseline values $(14.2 \pm 1.0 \mathrm{~kg})$. The results of this study seem to show that a six-cycle treatment with an oral contraceptive containing CMA-EE is associated with a decrease in fat mass. ${ }^{28}$ This is unexpected in light of previous studies of other contraceptives containing different progestin compounds, such as LNG and DRSP, which did not show similar effects on fat mass. ${ }^{20,30}$ The effect of CMA-EE in reducing fat mass is important in preventing cardiovascular disease, diabetes, and breast cancer, and is also important for women afraid of gaining weight during hormonal contraception. ${ }^{29}$

The reported adverse events with CMA-EE reflect the spectrum of complaints usually observed during use of oral contraceptives. The most frequently reported adverse events observed for the first time by participants in CMA-EE studies were headache $(37.4 \%)$, nausea $(23.1 \%)$, breast tenderness $(21.7 \%)$, and vaginal discharge (19.4\%). The description of symptoms showed maximum occurrence at the start of use, with a decrease in all symptoms in the following cycles. Some serious adverse events also occurred. Accidents and musculoskeletal injuries occurred in $0.66 \%$ of women, along with ovarian cyst surgery $(0.42 \%)$, hearing impairment $(0.18 \%)$, and goiter $(0.18 \%)$. Two proven cases of deep venous thrombosis and one case of pulmonary embolism occurred during the study. ${ }^{13}$ Similar findings have been reported in a postmarketing surveillance study in 2620 women. Only one adverse event was found in $85.4 \%$ in women, whereas $13.0 \%$ and $1.7 \%$, respectively, recorded two or three adverse events. The most frequently reported adverse events, observed by women for the first time whilst on the study medication or which intensified during the observation period, were breast pain in $4.6 \%$, migraine/ headache in $2.7 \%$, gastrointestinal disorders and weight gain in $0.9 \%$, and a depressive state in $0.8 \%$. With longer duration of CMA-EE intake, the occurrence of adverse events became less frequent. It was also reported that $32.3 \%$ of adverse events were evaluated as mild, $34.6 \%$ as moderate, and $23.4 \%$ as severe. One case of deep venous thrombosis was identified. ${ }^{14}$
During an extended regimen of CMA-EE (2 $\mathrm{mg}$ and $20 \mu \mathrm{g}$, respectively) in 147 women over 424 months of observation, no unexpected (including serious) adverse events were observed. The most frequent adverse events, ie, headache, breast pain, nausea, and tiredness are known to be associated with oral contraceptive use. There was only one thromboembolic event that occurred in a woman aged $>30$ years who smoked and had also experienced a recent period of immobility as a result of a twisted ankle. ${ }^{16}$

\section{Acceptability}

The CMA-EE combination is well tolerated from the perspective of both women and clinicians. In one study, after 12 cycles of treatment, almost $85 \%$ of women and more than $90 \%$ of clinicians have reported tolerability to be "very good" or "good". ${ }^{14}$ Only a minority of women (4.4\%) and clinicians $(1.4 \%)$ assessed tolerability to be "moderate" or "poor", and $76.4 \%$ of women expressed a wish to continue with CMA-EE after the end of the study.

Similar data were found for women who decided to switch to CMA-EE from other contraceptive. Well-being was reported by $85.9 \%$ of women as "very good" or "good", while $61 \%$ rated it as moderate, and only $1.6 \%$ described poor well-being. Compared with their previous contraceptive regimen, $80.5 \%$ of women reported being more satisfied or much more satisfied with CMA-EE. ${ }^{21}$

CMA-EE was also assessed as "very good" in terms of both physical and emotional symptoms by more than $90 \%$ of women using this contraceptive. General well-being was reported by $93 \%$ of women. ${ }^{15}$

\section{Disclosure}

The authors report no conflicts of interest in this work.

\section{References}

1. Handy RW, Palmer KH, Wall ME, Piantadosi C. The metabolism of antifertility steroids: The in vitro metabolism of chlormadinone acetate. Drug Metab Dispos. 1974;2(3):214-220.

2. Kuhl H. Pharmacokinetics of oestrogens and progestogens. Maturitas. 1990;12(3):171-197.

3. Neumann F. The antiandrogen cyproterone acetate: Discovery, chemistry, basic pharmacology, clinical use and tool in basic research. Exp Clin Endocrinol. 1994;102(1):1-32

4. Rabe T, Kowald A, Ortmann J, Rehberger-Schneider S. Inhibition of skin 5 alpha-reductase by oral contraceptive progestins in vitro. Gynecol Endocrinol. 2000;14(1):223-230.

5. Neumann F. The physiological action of progesterone and the pharmacological effects of progestogens: A short review. Postgrad Med J. 1978;54 Suppl 2:S11-S24.

6. Belara ${ }^{\circledR}$ product monograph. 1st ed. Grünenthal, GmbH, Germany.

7. Kuhl H. Chemie und pharmakologie von chlormadinonacetat. In: Loch EG, Schramm G, editors. Chlormadinonacetat bei Androgenisierungserscheinungen. Stuttgart: Schattauer; 1995. 
8. van der Vange N, Blankenstein MA, Kloosterboer HJ, Hasples AA, Thijssen JH. Effects of seven low-dose combined oral contraceptives on sex hormone binding globulin, corticosteroid binding globulin, total and free testosterone. Contraception. 1990;41(4):345-352.

9. Gallegos AJ, Gonzales-Diddi M, Merino M, et al. Tissue localisation of radioactive chlormadinone acetate and progesterone in the human. Contraception. 1970;1:151-161.

10. Handy RW, Hess TR, Wall ME. Comparative metabolism of chlormadinone acetate. [Abstract]. The Pharmacologist. 1973;15:228-233.

11. Terlinden R, Uragg H, Gohler K, Kneip C. Pharmacokinetics of chlormadinone acetate following single and multiple oral dosing of chlormadinone acetate $(2 \mathrm{mg})$ and ethinylestradiol $(0.03 \mathrm{mg})$ and elimination and clearance of a single dose of radiolabeled chlormadinone acetate. Contraception. 2006;74(3):239-244.

12. Spona J, Binder N, Höschen K, Feichtinger N. Contraceptive efficacy and safety of a low-dose oral contraceptive, $(0.03 \mathrm{mg}$ ethinyl oestradiol and $2 \mathrm{mg}$ chlormadinone acetate) Belara ${ }^{\circledR}$, over three medication cycle. Eur J Contracept Reprod Health Care. 2008;13(1):39-48.

13. Zahrandnik HP, Goldberg J, Andreas JO. Efficacy and safety of the new antiandrogenic oral contraceptive Belara. Contraception. 1998; 57(2):103-109.

14. Schramm G, Steffens D. A 12-months evaluation of the CMAcontaining oral contraceptive Belara: Efficacy, tolerability and antiandrogenic properties. Contraception. 2003;67(4):305-312.

15. Heskamp ML, Schramm GA. Efficacy of the low-dose combined oral contraceptive chlormadinone acetate/ethinylestradiol: Physical and emotional benefits. Contraception. 2010;81(1):49-56.

16. Brucker C, Hedon B, The HS, Höschen K, Binder N, Christoph A. Long-term efficacy and safety of a monophasic combined oral contraceptive containing $0.02 \mathrm{mg}$ ethinylestradiol and $2 \mathrm{mg}$ chlormadinone acetate administered in a 24/4-day regimen. Contraception. 2010; 81(6):501-509

17. Worret I, Arp W, Zahradnik HP, Andreas JO, Binder N. Acne resolution rates: Results of a single-blind randomized controlled parallel phase III trial with EE/CMA (Belara) and EE/LNG (Microgynon). Dermatology. 2001;203(1):38-44.

18. Plewig G, Cunliffe W, Binder N, Hoesschen K. Efficacy of an oral contraceptive containing EE $0.03 \mathrm{mg}$ and CMA $2 \mathrm{mg}$ (Belara) in moderate acne resolution: A randomized, double-blind, placebo-controlled Phase III trial. Contraception. 2009;80(1):25-33.

19. Kerscher M, Reuther T, Bayrhammer J, Schramm G. Effects of an oral contraceptive containing chlormadinone and ethinylestradiol on acneprone skin of women of different age groups: An open-label, singlecentre, Phase IV study. Clin Drug Investig. 2008;28(11):703-711.

20. Schramm G, Heckes B. Switching hormonal contraceptives to a chlormadinone acetate-containing oral contraceptive. The contraceptive switch study. Contraception. 2007;76(2):84-90.
21. Sabatini R, Orsini G, Cagiano R, Loverro G. Noncontraceptive benefits of two combined oral contraceptives with antiandrogenic properties among adolescents. Contraception. 2007;76(2):342-347.

22. Winkler UH, Daume E, Sudik R, et al. A comparative study of the hemostatic effects of two monophasic oral contraceptives containing $30 \mathrm{mcg}$ ethinylestradiol and either $2 \mathrm{mg}$ chlormadinone acetate or $150 \mathrm{mcg}$ desogestrel. Eur J Contracept Reprod Health Care. 1999;4: $145-154$.

23. Winkler UH, Röhm P, Höschen K. An open-label, comparative study of the effects of a dose-reduced oral contraceptive containing $0.02 \mathrm{mg}$ ethinylestradiol $/ 2 \mathrm{mg}$ chlormadinone acetate on hemostatic parameters and lipid and carbohydrate metabolism variables. Contraception. 2010; 81(5):391-400.

24. Winkler UH, Sudik R. The effects of two monophasic oral contraceptives containing $30 \mathrm{mcg}$ of ethinylestradiol and either $2 \mathrm{mg}$ of chlormadinone acetate or $0.15 \mathrm{mg}$ of desogestrel on lipid, hormone and metabolic parameters. Contraception. 2009;79(1):15-23.

25. Cagnacci A, Ferrari S, Tirelli A, Zanin R, Volpe A. Insulin sensitivity and lipid metabolism with oral contraceptives containing chlormadinone acetate or desogestrel: A randomized trial. Contraception. 2009; 79(2):111-116.

26. Zahradnik HP, Hanjalic-Beck A. Efficacy, safety and sustainability of treatment continuation and results of an oral contraceptive containing $30 \mathrm{mcg}$ ethinyl estradiol and $2 \mathrm{mg}$ chlormadinone acetate, in long-term usage (up to 45 cycles) - an open-label, prospective, noncontrolled, office-based Phase III study. Contraception. 2008;77(5):337-343.

27. Schramm G, Steffens D. Contraceptive efficacy and tolerability of chlormadinone acetate $2 \mathrm{mg}$ ethiniylestradiol $0.03 \mathrm{mg}$ (Belara). Clin Drug Investig. 2002;22(4):221-231.

28. Uras R, Orrù M, Etzi R, et al. Evidence that in healthy young women, a six-cycle treatment with oral contraceptive containing $30 \mathrm{mcg}$ of ethinylestradiol plus $2 \mathrm{mg}$ of chlormadinone acetate reduces fat mass. Contraception. 2009;79(2):117-121.

29. Fruzzetti F, Lello S, Lazzarini V, et al. The oral contraceptive containing 30 microg of ethinylestradiol plus $3 \mathrm{mg}$ of drospirenone is able to antagonize the increase of extracellular fluid occurring in healthy young women during the luteal phase of the menstrual cycle: An observational study. Contraception. 2007;75(3):199-203.

30. Lello S, Vittori G, Paoletti AM, Sorge R, Guardianelli F, Melis GB Effects on body weight and body composition of a low-dose estroprogestin containing ethinylestradiol 20 microg plus levonorgestrel 100 microg. Gynecol Endocrinol. 2007;23(11):632-637.
Open Access Journal of Contraception

\section{Publish your work in this journal}

Open Access Journal of Contraception is an international, peerreviewed, open access, online journal, publishing original research, reports, reviews and commentaries on all areas of contraception. In addition to clinical research, demographics and health-related aspects, the journal welcomes new findings in animal and preclinical studies

\section{Dovepress}

relating to understanding the biological mechanisms and practical development of new contraceptive agents. The manuscript management system is completely online and includes a very quick and fair peer-review system. Visit http://www.dovepress.com/testimonials.php to read real quotes from published authors. 